\title{
Puesta a punto de dispositivos para ensayos de digestión anaeróbica
}

\section{Development of devices for anaerobic digestion tests}

Presentación: 06/10/2020

\section{Doctorando:}

\section{Margarita Cesano}

Grupo de Investigación de Biogás y Aguas Residuales, Centro de Investigaciones en Toxicología Ambiental y Agrobiotecnología del Comahue (CITAAC) /Consejo Nacional de Investigaciones Científicas y Técnicas - Universidad Nacional del Comahue, Neuquén Argentina

margarita.cesano@gmail.com

\section{Director/a:}

\section{Marcela Noemí Gatti}

\section{Co-director/a:}

\section{Alberto Camacho}

\section{Resumen}

La Digestión Anaeróbica (DA) permite tratar residuos orgánicos y transformarlos en productos con valor agregado: el biogás y el digerido. En el presente trabajo se confeccionaron y testearon dispositivos para ensayos de DA en modalidad discontinua de $530 \mathrm{ml}$ (Dispositivo tipo 1) y semi-continua de $5.62 \mathrm{~L}$ (Dispositivo tipo 2). El Dispositivo 1 logró validarse por medio de ensayos con orujo de manzana, realizados por triplicado, con una producción de biogás de $142 \pm 6.6 \mathrm{ml}$ y de $\mathrm{CH}_{4}$ de $102.7 \pm 9.8$ $\mathrm{ml}$ y se corroboró que el agregado de cáscara de huevo mejora en un $43.06 \%$ la generación de $\mathrm{CH}_{4}$. Otro estudio, realizado con orujo de manzana y macroalgas en distintas proporciones, mostró los valores más altos de $\mathrm{CH}_{4}$ para la DA con $100 \%$ orujo $(224.33 \pm 21.59 \mathrm{ml})$, seguido por $50-50 \%$ orujo-macroalgas $(92.5 \pm 14.73 \mathrm{ml})$ y por último, $100 \%$ macroalgas $(6.17 \pm 2.93 \mathrm{ml})$. En el Dispositivo tipo 2 se realizaron pruebas de generación de inóculo a partir de lodo anaeróbico de río, y estudios con orujo de manzana y purín de cerdo, que permitieron testear la aptitud del diseño y sugerir mejoras.

Palabras clave: Biogás, Metano, Orujo, Macroalgas, Dispositivos.

\begin{abstract}
Anaerobic Digestion (AD) allows treating organic waste and transforming it into value-added products: biogas and digested. In the present work, devices were made and tested for $\mathrm{AD}$ assays in discontinuous mode of $530 \mathrm{ml}$ (Device type 1) and semicontinuous of 5.62 L (Device type 2). Device type 1 was validated through tests with apple pomace, carried out in triplicate, with a biogas production of $142 \pm 6.6 \mathrm{ml}$ and $\mathrm{CH}_{4}$ of $102.7 \pm 9.8 \mathrm{ml}$ and it was confirmed that the addition of eggshell improves by $43.06 \%$ the generation of $\mathrm{CH}_{4}$. Another study carried out with apple pomace and macroalgae in different proportions, showed the highest $\mathrm{CH}_{4}$ values for DA with $100 \%$ pomace $(224.33 \pm 21.59 \mathrm{ml})$, followed by $50-50 \%$ pomace-macroalgae (92.5 $\pm 14.73 \mathrm{ml})$ and finally, $100 \%$ macroalgae $(6.17 \pm 2.93 \mathrm{ml})$. In type 2 Devices, inoculum generation tests were carried out from anaerobic river sludge and, studies with apple pomace and pig slurry, suggesting design improvements.
\end{abstract}

Keywords: Biogas, Methane, Pomace, Macroalgae, Devices. 


\section{Introducción}

La fruticultura es una de las actividades productivas de mayor desarrollo en la zona del Alto Valle de Río Negro y Neuquén, orientada principalmente hacia la producción de manzana y pera. Una parte de la misma es destinada para la generación de jugos y sidras, proceso que genera como residuo un material sólido denominado orujo, constituido por pulpa de fruta, cáscaras, semillas y pedúnculo. El mismo está conformado fundamentalmente por agua (80\%), glúcidos, fibras, vitaminas, sales minerales, proteínas, grasas, aromas y pigmentos (Henry, Pahun, \& Trigo, 2014). El cultivo de la vid también tiene un rol protagónico, cuyo destino principal es la producción de vinos. El residuo sólido generado en el proceso de elaboración se denomina también orujo; está constituido por hollejo y semillas, representa un $25 \%$ de la materia prima utilizada y contiene aproximadamente un $89 \%$ de sólidos volátiles. Por su parte, la proliferación de cervecerías de pequeña y mediana escala aportó otro tipo de residuos necesarios de ser tratados, tales como malta (75\%), levaduras (20\%) y lúpulo (5\%) (Akunna, 2015).

La Digestión Anaeróbica (DA) es una tecnología que permite tratar residuos sólidos a la vez que genera productos con valor agregado, tales como el biogás y el digerido. Se ha demostrado que la complementariedad de los diversos residuos al ser tratados en co-digestión presenta ventajas frente a procesos de DA en monodigestión. Astorga y col han ensayado la codigestión de purín de con macroalgas de la región (Spirogyra sp), mostrando una generación de 157,2 $\pm 66,1 \mathrm{mlCH}_{4} / \mathrm{gSV}$, alrededor de tres veces más respecto a otros co-sustratos (Astorga M.; Gatti M.; Camacho A, 2019).

El desarrollo de dispositivos de bajo costo que permitan estudiar el PBM de los residuos generados en la zona resulta indispensable para potenciar el uso, alcance y difusión de la DA a nivel regional. Su construcción, testeo y validación ha sido el principal objetivo de este trabajo, junto con el testeo de sustratos y co-sustratos.

\section{Desarrollo}

\section{Muestreo}

$\begin{array}{ccc}\text { El } & \text { muestreo } & \text { de } \\ \text { residuos } & \text { orgánicos } & \text { se }\end{array}$ realizó en diferentes establecimientos de la zona del Alto Valle. Los orujos de uva y manzana fueron facilitados por bodegas y los residuos de malta, lúpulo y levadura por cervecerías locales. Las macroalgas de agua dulce fueron recolectadas de las orillas del río Limay (Neuquén) y las algas de agua salada del mar Argentino que baña la costa de la ciudad de Las Grutas (Río Negro). Ambas fueron identificadas por sus géneros: Spirogyra $y$

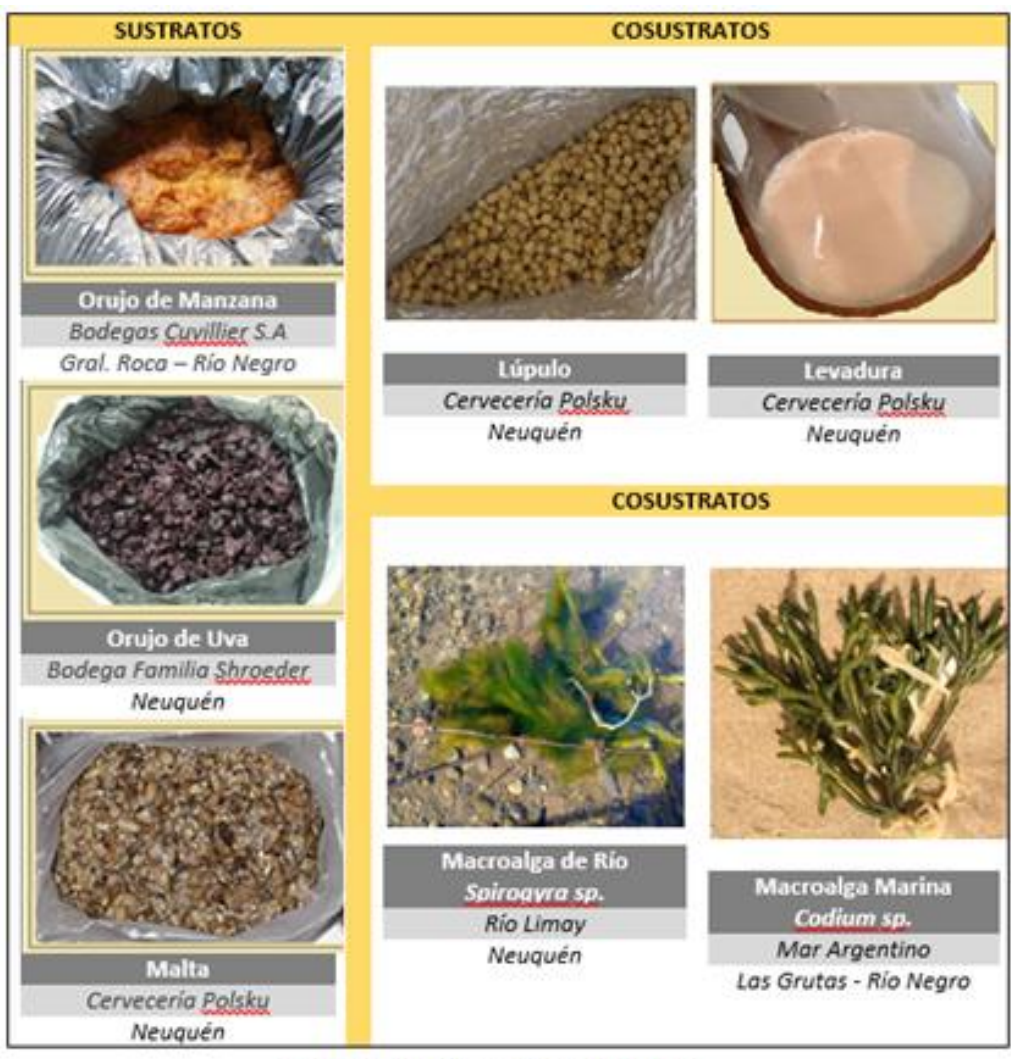

Figura 1: Muestras recolectadas
Codium, respectivamente (Figura 1). Una vez ingresadas en el laboratorio, las muestras fueron acondicionadas: aquellas provenientes de industrias fueron inspeccionadas

visualmente para la extracción de impurezas de gran tamaño, mientras que para las muestras de algas fue necesario realizar lavados sucesivos con agua destilada para separar la arena. A continuación, se realizó el fraccionamiento en bolsas de 200 gramos y fueron almacenadas en frío $\quad$ a $\quad-4^{\circ} \mathrm{C}$.

\section{Dispositivos:}

Los dispositivos utilizados fueron confeccionados con materiales reciclados y de bajo costo (Bartucci S., 2019). La hermeticidad fue testeada mediante inmersión completa en agua previo a su utilización con el fin de impedir el ingreso de oxígeno o la pérdida de biogás durante los ensayos de DA. 
- Dispositivo tipo 1: fue desarrollado para ensayos en modalidad discontinua. Se utilizó como biodigestor una botella de vidrio de $536 \mathrm{ml}$, sellada con un tapón de goma y conectada al gasómetro por medio de un tip de micropipeta p200 y de una manguera de silicona. El gasómetro consistió en un vaso de polipropileno de $750 \mathrm{ml}$ conteniendo una solución barrera saturada de $\mathrm{NaCl}$-con el fin de evitar la difusividad del biogás- y un vaso de acrílico transparente graduado de $200 \mathrm{ml}$ de capacidad, colocado en posición invertida, como contenedor del biogás. Se previó la incorporación de una llave de tres vías en la manguera de silicona para realizar la extracción de biogás con el uso de una jeringa (Fig. 2).

- Dispositivo tipo 2: fue desarrollado para ensayos en modalidad semi-continua. El biodigestor consistió en un recipiente de plástico semirrígido de 5.65 litros, adaptado de la siguiente manera: para el ingreso de la alimentación, se realizó

un orificio en la tapa, tanque de $1 / 2$ pulgada PVC orientada hacia el una longitud igual a $3 / 4$ mismo orificio se plegado para la la salida del digerido, sucesión de niples y invertida, ubicados a asegura un $20 \%$ de la recolección del acopló un gasómetro características que

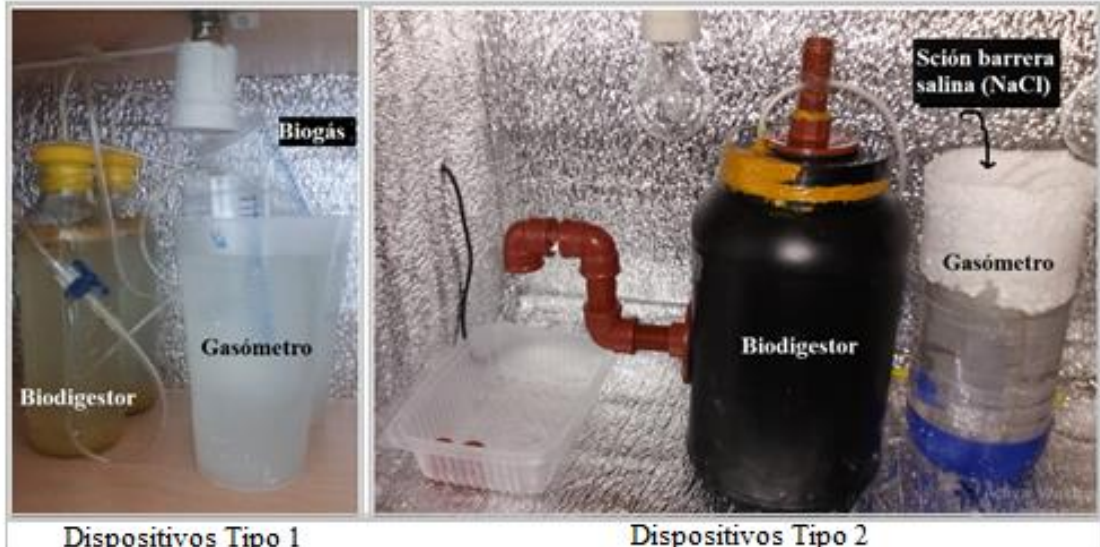

Figura 2: Dispositivos para DA de 1 litro de capacidad Este diseño fue utilizado tanto para la generación de inóculo como para los estudios con orujo de manzana.

\section{Metodología analítica:}

Las metodologías de análisis fueron implementadas de acuerdo al Standard Methods for Examination of Water and Wastewater (APHA, 2012). Se realizaron determinaciones de Sólidos Totales (ST), Sólidos Volátiles (SV), pH, Conductividad Eléctrica (CE) y potencial redox (ORP). Las determinaciones de Carbono Orgánico Total (COT) y Carbono Oxidable (Cox) se realizaron de acuerdo a la metodología de Walkley \& Black por microescala. La medición de biogás se realizó por lectura directa de la escala graduada marcada sobre cada gasómetro, y corroborando su volumen con jeringa en el caso del Dispositivo tipo 1, para minimizar el error debido al volumen manipulado. Para la determinación de $\mathrm{CH}_{4}$, se hizo pasar el biogás a través de una solución de $\mathrm{NaOH} 1 \mathrm{~N}$ para la retención del $\mathrm{CO}_{2}$ y se midió el volumen remanente.

\section{Inóculo:}

Dada la ausencia de fuentes de inóculo locales, se diseñó un ensayo para su producción a partir de lodo anaeróbico del fondo del lecho del río Limay. La temperatura de trabajo fue de $35^{\circ} \mathrm{C}$ y el Tiempo de Retención Hidráulico (TRH) de 30 días. Se lo alimentó durante 40 días alternando orujo de manzana (10 gr/carga), orujo de u va (10 gr/carga) y medio de cultivo con macro y micronutrientes $(100 \mathrm{ml} / \mathrm{carga})$, con 1 carga semanal (Holliger et al., 2016). Se añadieron al inicio $20 \mathrm{gr}$ de cáscara de huevo triturada. Se midió el pH durante todo el proceso.

\section{Ensayos de Digestión Anaeróbica}

En todos los casos, los ensayos se realizaron sin el agregado de inóculo, a una temperatura de $35^{\circ} \mathrm{C}$, y con una carga total SV de $1.24 \mathrm{~g} / \mathrm{kg}$.

- Ensayos en Dispositivos tipo 1: se realizaron dos estudios con diferentes fines, los cuales se describen a continuación: 
Estudio 1: el objetivo de este estudio consistió en testear la incidencia del agregado de cáscara de huevo en la producción biogás y $\mathrm{CH}_{4}$. Para ello se tomaron 3 dispositivos, correspondientes a R1: orujo con medio de cultivo, R2: orujo con medio de cultivo y cáscara de huevo, y el blanco. Se cargaron tal como se muestra en la Tabla 1.

\begin{tabular}{|c|c|c|c|c|c|}
\hline & Orujo (gr) & Cáscara de huevo (gr) & Medio de cultivo (ml) & pHo & pHi \\
\hline R1 & 8.21 & - & 458.00 & 3.43 & 7.2 \\
\hline R2 & 8.21 & 5 & 458.00 & 3.43 & 7.3 \\
\hline Blanco & - & 5 & 458.00 & 5.8 & 7.2 \\
\hline
\end{tabular}

Tabla 1

Se utilizó un medio de cultivo con macro y micronutrientes. La cáscara de huevo se trituró previamente a su incorporación en R2 y Blanco. El estudio se realizó con una sola repetición, respetando un espacio de cabeza del 13\%. Dado el carácter ácido del orujo (pHo), se llevó a pH neutro (pHi) con el agregado de $\mathrm{NaOH} 1 \mathrm{~N}$.

Estudio 2: el objetivo de este estudio consistió en comparar la producción de biogás y metano al añadir diferentes proporciones de orujo de manzana y macroalga de río. Se realizaron tres ensayos comparativos con cargas de: 100\% orujo (R3), 50\% orujo $-50 \%$ macroalgas (R4) y 100\% macroalgas (R5). En la Tabla 2 pueden observarse las cantidades añadidas.

\begin{tabular}{|c|c|c|c|c|}
\hline & Orujo (gr) & Macroalga (gr) & Cáscara de huevo (gr) & Medio de cultivo (ml) \\
\hline R3 & 8.22 & - & 5.00 & 416.58 \\
\hline R4 & 4.11 & 46.23 & 5.00 & 374.46 \\
\hline R5 & - & 92.47 & 5.00 & 332.33 \\
\hline Blanco & - & - & 5.00 & 424.80 \\
\hline
\end{tabular}

Tabla 2

El contenido se SV de la carga fue en todos los casos de $1.24 \mathrm{~g} \mathrm{SV} / \mathrm{kg}$, correspondiendo a diferentes cantidades según las proporciones orujo-macroalgas, debido a la diferencia significativa en contenido de SV (93.98 \pm 1.59 y $21.13 \pm 4.03$, respectivamente). La macroalga fue disgregada manualmente previamente a ser pesada. En todos los casos se agregaron 5 gr de cáscara de huevo. Los ensayos se realizaron por triplicado.

- Ensayos en Dispositivos tipo 2: los estudios se realizaron con un volumen de trabajo de 4.42 litros, con un $20 \%$ de espacio de cabeza. Se consideró un TRH de 30 días a $35^{\circ} \mathrm{C}$. El mismo se cargó inicialmente con restos de digerido de ensayos de DA, y en el día 7 comenzó a alimentarse con 12.43 gr orujo de manzana verde como sustrato (densidad: 0.996, $\% \mathrm{ST}=21.13, \mathrm{SV}(\mathrm{g} / \mathrm{kg})=207.27)$ y $331 \mathrm{ml}$ de purín como diluyente (densidad: $1.01, \% \mathrm{ST}=2.63, \mathrm{SV}(\mathrm{g} / \mathrm{kg})=0.64)$ con una frecuencia de 3 veces por semana. Se registró el volumen de biogás y $\mathrm{CH}_{4}$ producidos, el nivel de combustión del metano, el $\mathrm{pH}$, la conductividad eléctrica $(\mathrm{mS})$ y el potencial redox (mv). La Carga Orgánica Volumétrica (COV) testeada fue de 0.25 gr SV/L*día. El ensayo se sostuvo durante 37 días.

\section{Resultados:}

Caracterización:

En la tabla 3 se muestran los resultados de la caracterización fisicoquímica de los sustratos y co-sustratos seleccionados. Puede observarse que el porcentaje de SV de los sustratos es elevado, ubicando a la malta en primer lugar, seguida por el orujo de uva y por último el orujo de manzana. El pH ácido de los dos últimos sugiere que el suministro de capacidad buffer deberá estar garantizado en los ensayos de DA en los cuales se utilicen como sustratos. El lúpulo y la levadura son prometedores cosustratos dado su contenido en SV y el estado de agregación con el que salen de las plantas de producción de cerveza, que sugiere una alta biodisponibilidad. Antecedentes respecto al aumento de $\mathrm{CH}_{4}$ producido por agregado de Spirogyra sp. posicionan a Codium sp. como un co-sustrato interesante de explorar, dado su elevado contenido en SV. 


\begin{tabular}{|l|c|c|c|c|c|c|c|}
\hline & $\mathbf{S T}(\mathbf{g} / \mathbf{k g})$ & $\mathbf{S V}(\mathbf{g} / \mathbf{k g})$ & $\mathbf{\%} \mathbf{S V}$ & $\mathbf{p H}$ & $\begin{array}{c}\text { Conductividad } \\
(\mathbf{m v})\end{array}$ & $\begin{array}{c}\text { \% Cox (BH) } \\
(\mathbf{g} / \mathbf{1 0 0 g})\end{array}$ & \% COT (BH) \\
\hline SUSTRATOS & & & & & & & \\
\hline $\begin{array}{l}\text { Orujo de } \\
\text { Manzana }\end{array}$ & $160.48 \pm 4.26$ & $150.85 \pm 5.65$ & $93.98 \pm 1.59$ & 3.52 & $195 \pm 0.05$ & $10.92 \pm 0.08$ & $14.2 \pm 0.10$ \\
\hline Orujo de Uva & $95.80 \pm 2.69$ & $85.66 \pm 2.53$ & $89.42 \pm 0.71$ & 3.57 & $196 \pm 0.05$ & $5.91 \pm 0.03$ & $7.68 \pm 0.04$ \\
\hline $\begin{array}{l}\text { Residuo de } \\
\text { Malta }\end{array}$ & $249.49 \pm 2.69$ & $236.85 \pm 6.35$ & $94.94 \pm 2.72$ & 4.74 & $127 \pm 0.05$ & $15.81 \pm 0.13$ & $20.56 \pm 0.17$ \\
\hline CO-SUSTRATOS & & & & & & & \\
\hline Levadura & $147.47 \pm 2.60$ & $136.67 \pm 2.40$ & $92.67 \pm 0.07$ & - & - & $3.35 \pm 0.05$ & $4.36 \pm 0.06$ \\
\hline Lúpulo & $158.26 \pm 1.33$ & $152.19 \pm 1.41$ & $96.17 \pm 0.13$ & - & - & - & - \\
\hline $\begin{array}{l}\text { Macroalga } \\
\text { Río Limay }\end{array}$ & $65.48 \pm 14.10$ & $13.41 \pm 0.23$ & $21.13 \pm 4.03$ & - & - & $1.75 \pm 0.11$ & $2.28 \pm 0.14$ \\
\hline $\begin{array}{l}\text { Macroalga de } \\
\text { Mar }\end{array}$ & $59.13 \pm 0.21$ & $44.06 \pm 0.09$ & $74.51 \pm 0.10$ & - & - & $1.34 \pm 0.08$ & $1.74 \pm 0.10$ \\
\hline
\end{tabular}

Tabla 3

\section{Inóculo:}

La generación del inóculo no resultó satisfactoria debido a la pérdida de actividad biológica por acidificación del mismo. Si bien se trató de regular el $\mathrm{pH}$ por medio del agregado de $\mathrm{NaOH}$, no fue posible revertir dicha condición. Se estima que la carga de orujo pudo haber sido excesiva, no pudiendo ser degradada por el consorcio microbiano allí presente.

\section{Ensayos en discontinuo}

Estudio 1: Tal como puede observarse en la Figura 3a., la producción de biogás y $\mathrm{CH}_{4}$ para el biorreactor al que se le añadió orujo de manzana y cáscara de huevo (R1, 285 y $209 \mathrm{ml}$ ) resultó significativamente mayor que aquél con orujo solo (R2, 115 y $90 \mathrm{ml})$. El blanco pone en evidencia que la producción de biogás $(7 \mathrm{ml})$ y $\mathrm{CH}_{4}(5 \mathrm{ml})$ por parte de la cáscara de huevo es muy baja, sugiriendo que su beneficio en R1 de debió principalmente al aporte de capacidad buffer y no de SV. La duración total del ensayo fue de 5 días. La producción de $\mathrm{CH}_{4}$ en $\mathrm{R} 1$ fue durante 4 días y en $\mathrm{R} 2$ durante 3 días, mientras que el blanco solo produjo el día 1. Si se analizan las primeras 24 horas, puede observarse un incremento veloz en la generación de $\mathrm{CH}_{4}$ para $\mathrm{R} 2$, que puede atribuirse a la sinergia del orujo-cáscara de huevo para favorecer la metanización (Fig. 3b).

Es estudio se repitió por triplicado para el reactor con orujo solo, obteniendo una producción de $142 \pm 6.6 \mathrm{ml}$ de biogás y 122.7 $\pm 9.8 \mathrm{ml}$ de metano, validando el dispositivo utilizado y los resultados obtenidos previamente.

Estudio 2: El ensayo con 100\% orujo de manzana fue el qué mayor producción de metano alcanzó (224.33 $\pm 21.59 \mathrm{ml})$, duplicando al producido por la proporción 50-50\% (92.5 $\pm 14.73 \mathrm{ml})$. El estudio con $100 \%$ macroalga fue el menos favorecido en cuanto al volumen de $\mathrm{CH}_{4}$ generado $(6.17 \pm 2.93 \mathrm{ml})$. Tal como se muestra en la Figura 4 a., si se analizan las primeras 24 horas, puede observarse un incremento veloz en la generación de $\mathrm{CH}_{4}$ para $\mathrm{R} 3$. Esto puede deberse a que el orujo de manzana tiene materia orgánica fácilmente biodegradable, tal como azúcares simples, dado su procesado previo en la industria. En tal sentido, la macroalga no contó con un pretratamiento exhaustivo, dificultando su biodisponibilidad, y viéndose desfavorecida por la ausencia de inóculo con capacidad de hidrólisis.

\section{Ensayos en semi-continuo:}

En la Figura 4 b. puede observarse la evolución de la producción de $\mathrm{CH}_{4}$ a lo largo del ensayo. Los primeros 11 días fueron de adaptación de la biomasa microbiana y de ajustes del dispositivo. Recién a partir del día 12 pudo comenzarse con las mediciones de biogás y $\mathrm{CH}_{4}$ y se mantuvieron hasta el día 37. La proporción de $\mathrm{CH}_{4}$ el en biogás se mantuvo entre 70 y $88 \%$ y se observó un nivel creciente de la intensidad de la combustión en el tiempo. El salto significativo a partir del día 32 pudo deberse a dos cambios introducidos: (1) el ingreso del orujo mixeado con el purín, dada la dificultad de ingresarlos separados y (2) utilización de un purín nuevo, cuyo contenido de SV no alcanzó a determinarse. 

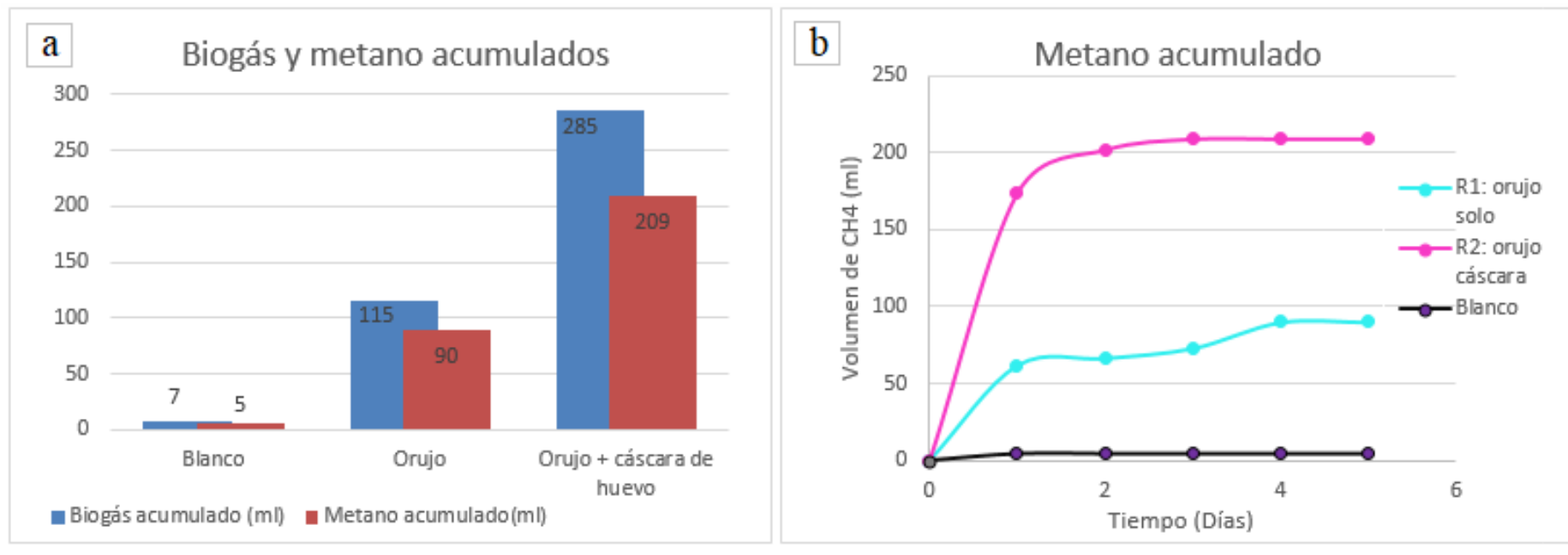

Figura 3: Testeo del Dispositivo tipo 1 (Estudio 1). a. Biogás y $\mathrm{CH}_{4}$ total acumulados. b. $\mathrm{CH}_{4}$ acumulado en el tiempo
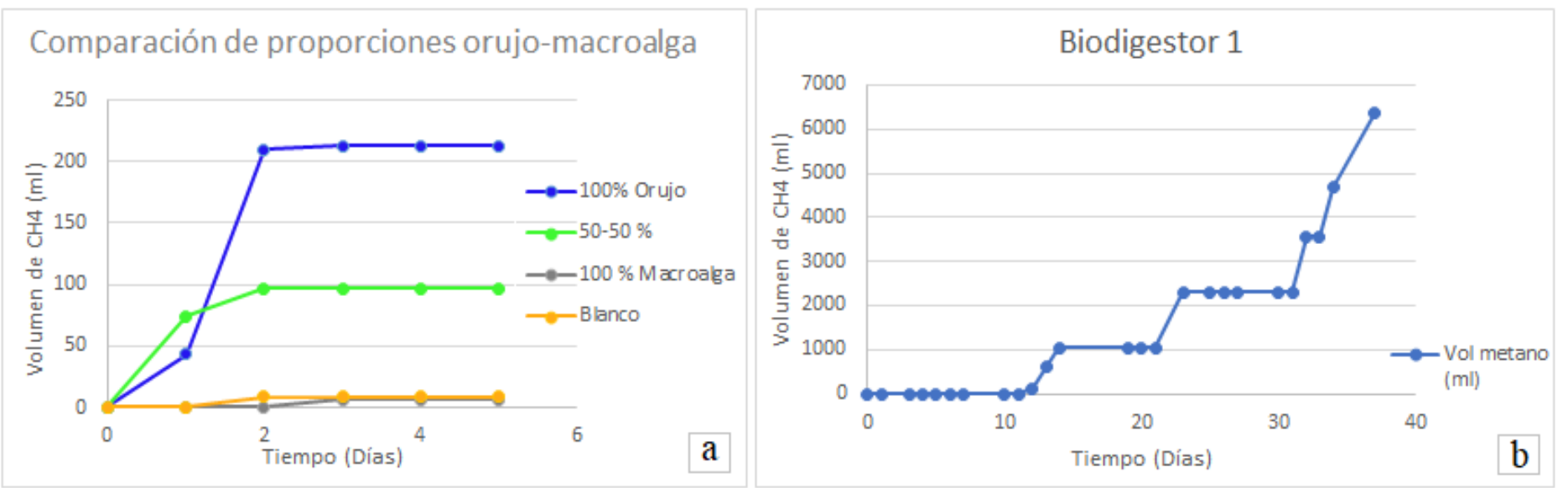

Figura 4: a. Testeo del Dispositivo tipo 1 (Estudio 2). b. Testeo del Dispositivo tipo 2 con orujo de manzana y purín de cerdo.

\section{Conclusiones}

Los dispositivos propuestos han sido de utilidad para los fines perseguidos, mostrando resultados repetibles en el caso del Dispositivo tipo 1 y aportando experiencia en el manejo de un proceso semi-continuo en el caso del Dispositivo tipo 2, sugiriendo algunas mejoras en el diseño para futuros ensayos. Respecto a los sustratos y co-sustratos testeados, puede concluirse que presentan características favorables para ser utilizados en la producción de $\mathrm{CH}_{4}$ y estudiados en ensayos de Potencial Bioquímico de Metano (PBM) con el agregado de inóculo.

\section{Referencias}

Akunna, J. C. (2015). Anaerobic treatment of brewery wastes. In Brewing Microbiology: Managing Microbes, Ensuring Quality and Valorising Waste. https://doi.org/10.1016/B978-1-78242-331-7.00019-8

APHA. (2012). Standard Methods for the Examination of Water and Wastewater, 22nd edition. American Public Health Association, American Water Works Association, Water Environment Federation. https://doi.org/10.1520/E0536-16.2

Astorga M.; Gatti M.; Camacho A. (2019). Co-digestión anaerobia de purines de cerdo con macrófi- tas acuáticas de la cuenca neuquina y residuos orgànicos derivados de la agroindustria patagònica. In A. V.-1a ed. - \& 2019. Buenos Aires: Asociación Química Argentina (Eds.), XXXII Congreso Argentino de Química (pp. 2-3). Buenos Aires, Argentina.

Bartucci S. (2019). Dispositivo de bajo costo para la medición de biogas. IV Jornadas de Investigación, Extensión y Posgrado, Universidad Nacional Del Comahue, 2019.

Henry, G., Pahun, J., \& Trigo, E. (2014). La Bioeconomía en América Latina: oportunidades de desarrollo e implicaciones de política e investigación. FACES: Revista de La Facultad de Ciencias Económicas y Sociales, 20(42), 125-141.

Holliger, C., Alves, M., Andrade, D., Angelidaki, I., Astals, S., Baier, U., ... Wierinck, I. (2016). Towards a standardization of biomethane potential tests. Water Science and Technology, 74(11), 2515-2522. https://doi.org/10.2166/wst.2016.336 